\title{
Identification of a Point Mutation Resulting in a Heat-labile Adenosine Deaminase (ADA) in Two Unrelated Children with Partial ADA Deficiency
}

\author{
Rochelle Hirschhorn, ${ }^{*}$ Stephanie Tzall, ${ }^{*}$ Amy Ellenbogen," and Stuart H. Orkin*5 \\ *Division of Human Genetics, Department of Medicine, New York University Medical Center, New York, New York 10016; and \\ ${ }^{\ddagger}$ Division of Hematology-Oncology, Children's Hospital Medical Center, Dana Farber Cancer Institute, Department of Pediatrics, and \\ ${ }^{\S}$ Howard Hughes Medical Institute, Harvard Medical School, Boston, Massachusetts 02115
}

\begin{abstract}
We have determined the mutation in a child with partial adenosine deaminase (ADA) deficiency who is phenotypically homozygous for a mutant ADA gene encoding a heat-labile enzyme (Am. J. Hum. Genet. 38:13-25). Sequencing of cDNA demonstrated a $\mathbf{C}$ to $\mathrm{A}$ transversion that results in the replacement of a proline by a glutamine residue at codon 297. As this mutation generated a new recognition site in exon 10 of genomic DNA for the enzyme Alu I, Southern blot analysis was used to establish that this child was indeed homozygous for the mutation. The abnormal restriction fragment generated by this mutation was also found in a second partially ADA-deficient patient who phenotypically is a genetic compound and also expresses a heat-labile ADA (in addition to a more acidic than normal ADA) (Am. J. Hum. Genet. 38:13-25). Sequencing of cDNA clones from the second patient established the identical codon 297 mutation. Transfection of the mutant cDNA into heterologous cells resulted in expression of a heat-labile ADA of normal electrophoretic mobility and isoelectric point, properties exhibited by the ADA in the patients' cells.
\end{abstract}

\section{Introduction}

Mutations at the adenosine deaminase (ADA) ${ }^{1}$ locus that diminish enzyme activity result in three overlapping phenotypes. Those mutations that result in virtually complete loss of enzyme activity in all cell types cause a rapidly fatal, infantile onset syndrome of severe combined immunodeficiency (SCID). In contrast, mutations that abolish enzyme activity in erythrocytes but allow expression of variable residual ADA in other cell types (partial ADA deficiency), are usually associated with normal immunologic function. However, at least two patients with partial ADA deficiency have presented with a late onset immunodeficiency syndrome (reviewed in Reference 1). Additionally, we have previously reported an apparently increased prevalence of partial ADA deficiency in popu-

Address correspondence to Dr. Rochelle Hirschhorn, Division of Human Genetics, Department of Medicine, New York University Medical Center, 550 First Avenue, New York, NY 10016.

Received for publication 2 June 1988 and in revised form 19 August 1988.

1. Abbreviations used in this paper: ADA, adenosine deaminase; RFLP, restriction fragment length polymorphism; SCID, severe combined immunodeficiency.

J. Clin. Invest.

(c) The American Society for Clinical Investigation, Inc.

0021-9738/89/02/0497/05 \$2.00

Volume 83, February 1989, 497-501 lations derived from the Caribbean, that phenotypically does not appear to be due to the spread of a single mutation (2). To further elucidate the molecular basis for this clustering of partial ADA deficiency among individuals from the Caribbean as well as for the clinical heterogeneity, we have sought to define the mutant genes and examine their function in vitro. From sequence analysis of cDNA we have now determined the mutation in a partially ADA-deficient child from Santo Domingo who phenotypically appears to be homozygous for a mutant ADA gene coding for an enzyme that is labile at febrile temperatures (2). The single base substitution found resulted in an abnormal restriction fragment, which enabled us to determine that a second unrelated partially ADA-deficient child carried the same mutation.

\section{Methods}

\section{Materials}

Cell lines from the two partially ADA-deficient children (GM 6142 and $6143 \mathrm{~A}$ ) were obtained from the National Institutes of Health Genetic Mutant Repository, Camden, NJ. Both children were ascertained by the New York State Newborn Screening Program for ADA deficiency and determined to be partially ADA deficient (2, unpublished observations). The parents of both children came from Santo Domingo, but they were not related and did not have last names in common.

\section{Methods for analysis of DNA and RNA}

Isolation of DNA and RNA, electrophoresis in agarose gels, Southern and Northern blotting, and hybridization with radiolabeled cDNA probes were performed as we have previously described by essentially standard methods $(3,4)$. An ADA cDNA containing the complete coding sequence and extending from the Nae I site to the $3^{\prime}$ Nco I site was used as probe (5). For delineation of the abnormal restriction fragment generated by the exon 10 mutation, a cDNA fragment $(\mathrm{Bgl}$ II/Pst I) spanning exons 9-11 was used (6). RNA was extracted from normal and mutant lymphoid B cell lines by the method of Chirgwin et al. (7) as described by Adrian et al. (8) and mRNA was isolated by binding to and elution from oligo dT columns (4). Analysis of the structural integrity of mRNA was assessed by sensitivity of mRNAcDNA hybrids to digestion with $\mathrm{S} 1$ nuclease, essentially as described by Adrian (8), based on the methods of Favaloro (9). The probe used was a 1.45-kb single-stranded M13 clone containing the entire ADA cDNA antisense coding sequences and extending from the Nae I site to an Nco I site in the $3^{\prime}$ untranslated sequence (5).

The cDNA libraries were constructed in lambda gt 11 (10) essentially as described by Gubler and Hoffman (11). Primary platings of library cDNA were screened using randomly labeled ADA cDNA probes $(4,12)$. cDNA inserts were subcloned into M13 mp 19 or pUC 19 for the DNA sequence analysis using a series of ADA-specific primers (13-15).

\section{Transient and stable expression in heterologous cells}

Subcloning of the cDNA into pSV2-Hind III. Full-length cDNA insert was subcloned into the Eco RI site of Puc 13 and digested with Nco I 
and Hinf I to release a $1.125-\mathrm{kb}$ fragment containing the complete coding sequences and extending from 1 bp before the initiation ATG to $31 \mathrm{bp} 3^{\prime}$ of the stop codon $(5,6)$. The $3^{\prime}$ recessed ends were filled in using the Klenow fragment of DNA polymerase, ligated to phosphorylated Hind III linkers, and digested with Hind III. The cDNA fragment was isolated after electrophoresis in $1 \%$ low melt agarose and ligated into a unique Hind III site of the expression vector pSV2-Hind III (5). A clone was chosen in which the orientation of the cDNA was correct, the plasmid was amplified, and DNA was purified by centrifugation in cesium chloride (4).

Expression in heterologous cells and analysis of properties of the expressed $A D A . \operatorname{Cos} 1$ monkey kidney cells were grown to confluency in DME supplemented with $10 \% \mathrm{FCS}$, trypsinized, diluted to $0.5 \times 10^{6}$ cells $/ 100-\mathrm{mm}^{2}$ petri dish, and grown overnight. The cells were transfected with $15 \mu \mathrm{g}$ of plasmid DNA per petri by calcium phosphate precipitation as previously described (16) and $8 \mathrm{~h}$ later briefly exposed to $16.7 \%$ glycerol. Cells were grown for a total of $48 \mathrm{~h}$ from the time of transfection, rinsed, harvested by scraping, and lysed by brief sonication. The $10,000 \mathrm{~g}$ supernatant was analyzed for human ADA activity after electrophoresis in starch gel or isoelectric focusing as previously described $(2,17)$.

Stable transformants were isolated after transfection of mouse 3T3 cells with $0.5 \mu \mathrm{g}$ of pBR-Neo together with the ADA plasmid. Clones expressing the Neo gene (G418 resistant), were selected as we have previously described (16). 10 G418-resistant clones analyzed all expressed human ADA. For studies of heat stability, cells from a $75-\mathrm{cm}^{2}$ flask were resuspended in $40 \mu \mathrm{l} 0.01 \mathrm{M}$ phosphate buffer, $\mathrm{pH} 7.5$, briefly sonicated, one-half of a $10,000 \mathrm{~g}$ supernatant placed at $56^{\circ} \mathrm{C}$ for $15 \mathrm{~min}$, and ADA activity visualized after electrophoresis in starch gel $(2,17)$.

\section{Results}

Gross structure of the mutant ADA gene. The presence of substantial, albeit heat-labile, ADA in lymphoid cells of this child (GM 6142) (2) suggested that a missense mutation was responsible for the abnormal ADA. However, in view of expected genetic heterogeneity, the child might be a genetic compound for a single nucleotide substitution and a deletion which would result in a nonexpressed ADA. Therefore, genomic DNA and B cell mRNA from GM 6142 was examined for gross aberrations in structure of the ADA gene. No abnormal restriction fragments were seen after digestion of DNA with nine different enzymes (Eco RI, Hind III, Bgl II, Bal I, PVU II, Ban II, Msp I, Taq I, Pst I) and hybridization to a full-length cDNA probe. The child was homozygous for the most common haplotype defined by restriction fragment length polymorphisms (RFLPs) detected with five of these enzymes (13, 18, 19; Table I). The mRNA was normal in size and abundance. In addition, no digestion of mRNA-cDNA hybrids by $\mathrm{S} 1$ nuclease was observed (not shown).

Sequence of the mutant $A D A$ and detection of the same mutation in a second patient. To determine the molecular defect in this patient, ADA cDNA clones derived from immortalized B cells were studied. Complete sequencing of a fulllength cDNA clone revealed only a $\mathrm{C}$ to $\mathrm{A}$ transversion at nucleotide 890 (A of the initiation ATG = 1) (Fig. 1). The same base substitution was found in two additional cDNA clones. Two of the three clones began $\sim 30$ bp upstream of the previously reported site of initiation $(20,21)$. This replacement results in the substitution of a glutamine for a proline residue in codon 297 (6).

The base substitution predicts the generation of a new site for the enzyme Alu I in exon 10, which should result in loss of
Table I. Identity of RFLPs and Silent Polymorphic Base Pair Substitutions

\begin{tabular}{|c|c|c|}
\hline Polymorphic sites & GM 6142 & GM 6143A \\
\hline \multicolumn{3}{|l|}{$\mathrm{bp}^{*}$} \\
\hline $192(\mathrm{G} / \mathrm{A})$ & G/G & G/ND \\
\hline $239(A / G)$ & A/A & $\mathrm{A} / \mathrm{ND}$ \\
\hline $330(\mathrm{C} / \mathrm{T})$ & $\mathrm{C} / \mathrm{C}$ & $\mathrm{C} / \mathrm{ND}$ \\
\hline 390 (G/A) & $\mathrm{G} / \mathrm{G}$ & G/ND \\
\hline $534(\mathrm{~A} / \mathrm{G})^{\ddagger}$ & A/A & A/ND \\
\hline \multicolumn{3}{|l|}{ RFLPs $^{\S}$} \\
\hline Pst I IVS 2 (-) & $-1-$ & $-1+$ \\
\hline Msp I IVS $3(+)$ & $+/+$ & $+1+$ \\
\hline Msp I IVS $5(+)$ & $+/+$ & $+/+$ \\
\hline Msp I IVS $6(+)$ & $+/+$ & $+/+$ \\
\hline Msp I IVS $8(+)$ & $+/+$ & $+1+$ \\
\hline Msp I IVS $10(+)$ & $+1+$ & $+/+$ \\
\hline Bal I exon $6(-)^{\ddagger}$ & $-1-$ & $-1-$ \\
\hline Pvu II IVS 8 (-) & $-1-$ & $-1-$ \\
\hline Ban II IVS 4 (+) & $+/ t$ & $+/+$ \\
\hline
\end{tabular}

* The base found most frequently is listed first. The bases are numbered with the $\mathrm{A}$ of the ATG $=1$.

₹ The Bal I RFLP and the basepair substitution at bp 534 are synonymous.

$\S$ For RFLPs $(+)$ indicates the presence of the restriction site. The most frequent form is indicated in parentheses. The assignment of haplotypes in GM6143A is based on family studies (not shown).

a $0.585-\mathrm{kb}$ fragment and appearance of smaller 0.321 - and 0.264-kb fragments (22) as detected by a Bgl II/Pst I cDNA probe spanning exons 9-11. Analysis of genomic DNA from GM 6142 digested with Alu I revealed loss of an $\sim 0.6-\mathrm{kb}$ fragment and appearance of a smaller fragment (Fig. 2). The loss of the 0.6-kb fragment and concomitant appearance of an abnormal fragment is consistent with homozygosity for this mutation.

We next sought to determine if any additional partially ADA-deficient individuals, particularly those exhibiting a heat-labile enzyme, also exhibited this abnormal Alu I fragment. One other partially ADA-deficient child (GM 6143 A) who is a genetic compound expressing a heat-labile ADA and an acidic ADA (1) also showed a smaller abnormal Alu I fragment with approximately half the intensity of that seen in GM

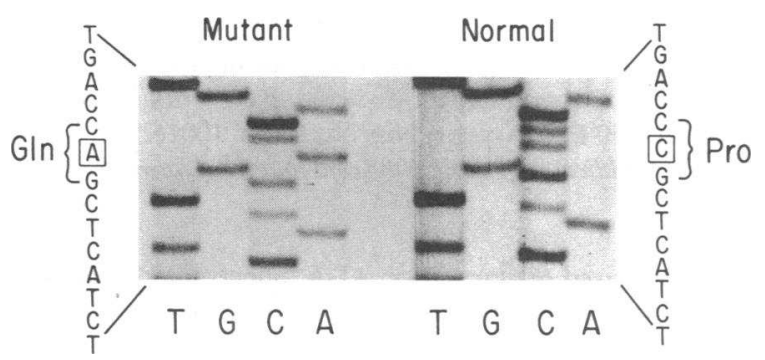

Figure 1. Nucleotide sequence of mutant and normal cDNAs. There is a C to A transversion at bp 890 (bp $1=\mathrm{A}$ of the first ATG). The mutation occurs at codon 297 and results in replacement of a proline (CCG) by a glutamine (CAG). 

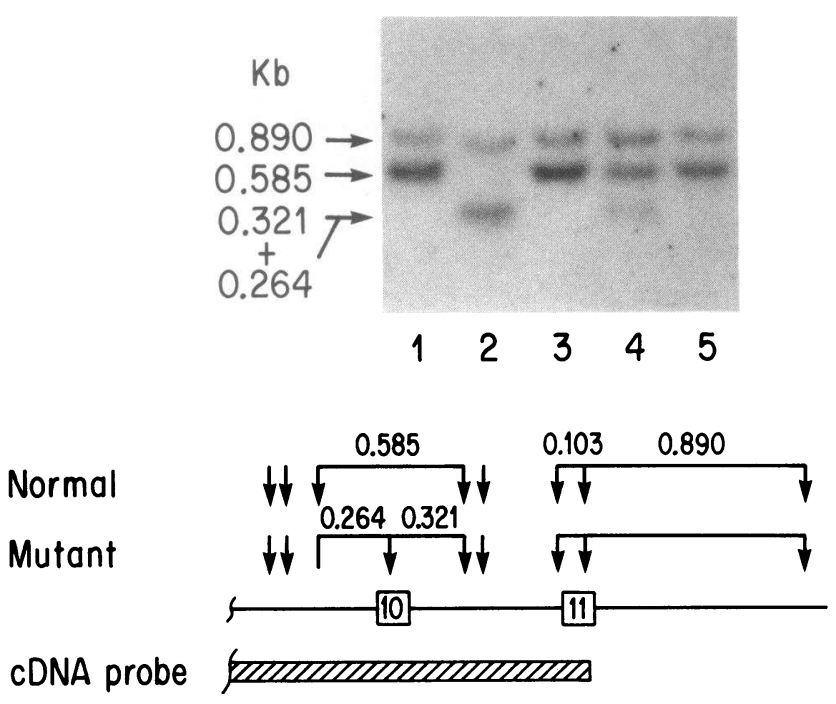

Figure 2. Abnormal restriction fragments resulting from the mutation. A C to A transversion in exon 10 creates a new site for the restriction enzyme Alu I. This results in abnormal restriction fragments as well as loss of a normal fragment after digestion with Alu I and hybridization with a cDNA probe containing exons 9-11. Normal, lanes 1,3 , and 5; GM 6142, lane 2 (the 0.585 -kb band containing exon 10 is absent, indicating homozygosity for the mutation, and has been replaced by two smaller comigrating bands); GM 6143, lane 4 (the $0.585-\mathrm{kb}$ band is still present but diminished in intensity as compared with the $0.890-\mathrm{kb}$ exon 11 band, and the abnormal band is half the intensity of the band in GM 6142, consistent with heterozygosity for the mutation in GM 6143).

6142. (The 0.6-kb normal fragment was still present, representing the second allele bearing a different mutation.) The father of GM 6143A, who also expresses a heat-labile ADA, but together with a normal ADA, also exhibited the smaller abnormal Alu I fragment. None of 21 other individuals (11 normal, 7 partially ADA-deficient, and 3 with ADA-SCID) showed this abnormal Alu I fragment. The identity of the mutation in the two patients was confirmed by sequencing of two cDNA clones from this second patient.

Since the same mutation can occur on different chromosomal backgrounds $(23,24)$ we also determined RFLPs at the ADA locus, as well as additional polymorphic basepair changes. The DNA sequence at each of the five polymorphic sites in the coding portion of ADA cDNA was identical in cDNAs from both children (Table I) with the most common nucleotide occurring at each site $(13,24)$. One child was homozygous for the common haplotype defined by eight RFLPs at the ADA locus $(13,18,19)$ while the second child was heterozygous for an RFLP detected after digestion with Pst I (18), consistent with his phenotype as a genetic compound (2). Family studies (data not shown) confirm that the Pst I RFLP in GM 6143 is on the chromosome bearing a different mutation.

Comparison of the properties of the cloned and endogenous mutant $A D A$. To determine if the isolated mutant cDNA coded for an enzyme with the properties of the mutant ADA expressed in the lymphoid cells of the patients, we inserted the coding portions of the cDNA into an SV40-derived expression vector and transiently expressed the mutant cDNA in COS 1 monkey kidney cells. The ADA transiently expressed by the cloned ADA cDNA had a normal mobility after electrophoresis in starch gel and a normal pI (not shown), properties exhibited by the enzyme found in the cells of these patients (2). To study heat stability of the mutant enzyme under more physiologic conditions, we next isolated stable transformants expressing the mutant ADA. The pSV2 ADA was cotransfected into mouse $3 \mathrm{~T} 3$ fibroblasts with a pSV neo plasmid specifying the dominant selectable Neo gene and stable transformants expressing human ADA isolated. The ADA expressed by the stable transformants exhibited the same normal electrophoretic mobility as the transiently expressed ADA and was labile to heat, as was the mutant ADA in the patients' cells (Fig. 3).

\section{Discussion}

Six different mutations at the ADA locus have previously been precisely defined in children with ADA deficiency and SCID $(13,24-27)$. We now report the first definition of a mutation that results in partial ADA deficiency in two unrelated children, both of whom express a heat-labile mutant ADA either alone or in combination with a second mutant ADA. The mutation is a $C$ to $A$ transversion at bp 890 and results in the replacement of a hydrophobic proline by a polar glutamine residue at codon 297 . The substitution occurs at a boundary between a turn and a beta configuration in the predicted secondary structure (6) and predicts a modest increase in hydrophylicity extending from a transition of a turn to a beta configuration and into the hydrophobic region of the beta configuration (Table II; 28-30), consistent with the increased lability to heat observed for this mutant enzyme (2). The mutation occurs seven codons preceeding a mutation in the same exon 10 detected in a patient with ADA-SCID (25). This latter mutation results in replacement of a hydrophobic leucine by the basic amino acid arginine at codon 304. According to the predicted secondary structure, the two different mutations occur at either side of a seven-amino acid stretch with a beta configuration. Both represent loss of hydrophobic amino acids, but in the case of the mutation resulting in total deficiency of ADA and SCID the replacement is by a very polar basic amino acid that is predicted to result in a major increase in hydrophylicity (26-28), extending back into the beta structure and altering the site of transition to a turn.

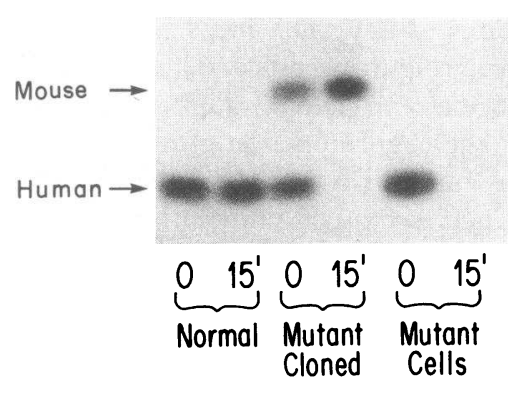

Figure 3. Heat lability of mutant ADA. Cell extracts were heated at $56^{\circ} \mathrm{C}$ for $15^{\prime}\left(15^{\prime}\right)$ or not heated $(0)$, electrophoresed in starch gel, and the gel stained for ADA activity $(1,17)$. Normal, normal B cell line; $m u$ tant, GM 6142 B cell line; mutant cloned, mouse $3 \mathrm{~T} 3$ cells stably transformed with the mutant cDNA. The upper band of enzyme activity is the endogenous murine ADA of the $3 \mathrm{~T} 3$ cells. 
Table II. Effects of Two Mutations in Exon 10 on Hydrophilicity

\begin{tabular}{lcrrr}
\hline Codon & $\begin{array}{c}\text { Secondary } \\
\text { structure* }\end{array}$ & Normal & $\begin{array}{c}\text { Mutant } \\
279^{\ddagger}\end{array}$ & $\begin{array}{c}\text { Mutant } \\
304^{8}\end{array}$ \\
\hline 292 & T & 1.357 & 1.357 & 1.357 \\
293 & T & 1.357 & 1.357 & 1.357 \\
294 & T & 1.400 & 1.671 & 1.400 \\
295 & T & 0.743 & 1.014 & 0.743 \\
296 & B & 0.643 & 0.914 & 0.643 \\
$297^{\ddagger}$ & B & -0.257 & 0.014 & -0.257 \\
298 & B & 0.200 & 0.471 & 0.200 \\
299 & B & -0.186 & 0.086 & -0.186 \\
300 & B & -0.586 & -0.314 & -0.586 \\
301 & B & -1.357 & -1.357 & -0.171 \\
302 & B & -0.314 & -0.314 & 0.871 \\
303 & - & 0.429 & 0.429 & 1.614 \\
$304^{\S}$ & . & 1.329 & 1.329 & 2.514 \\
305 & T & 0.957 & 0.957 & 2.143 \\
306 & T & 1.343 & 1.343 & 2.529 \\
307 & T & 0.971 & 0.971 & 2.157 \\
308 & T & 1.614 & 1.614 & 1.614 \\
& & & & \\
\hline
\end{tabular}

Analyzed by the GCG program based on Kyte-Doolittle $(26,28)$.

* Predicted secondary structure of normal as calculated by GCG based on Garnier-Osguthorpe-Robson (29).

‡ Proline to glutamine in GM 6142.

${ }^{\S}$ Leucine to arginine in GM 2434.

We have previously reported that there is an apparent increased prevalence of partial ADA deficiency in the Caribbean (2) that did not appear to reflect the spread of a single mutation due to "founder effect" combined with a high coefficient of inbreeding. Thus we defined at least six different mutations in six of these children on the basis of characterization of the mutant $\operatorname{ADAs}(2,31,32)$. We have now unambiguously demonstrated that there are indeed different mutations in this population, since we have identified one mutation that is present in two unrelated partially ADA-deficient children from the Caribbean but not in any of the other partially ADA-deficient children. One child is homozygous for the mutation while the second child is a genetic compound carrying a second mutation. Both children are unrelated, but since both derive from Santo Domingo it is likely that they represent descendants of a common ancestor carrying the mutation. In support of a common progenitor, the children showed the same changes at multiple polymorphic sites. However, since the haplotype on which this mutation occurs in both children is very common $(\sim 60 \%)$, there is still a substantial chance that the mutations occurred independently on different chromosomes not distinguishable by available markers $(13,18,19,24)$. The finding of multiple different mutations at the ADA locus in a limited geographic and ethnic background suggests a selective advantage for partial ADA deficiency in heterozygous or homozygous form. Alternatively, the chance fixation of one or more partial mutation(s) in a limited population (genetic drift) would then result in the increased ascertainment by a screening program for ADA deficiency of individuals who are genetic compounds carrying one or more common alleles for partial deficiency in combination with different unique partial or null alleles.

\section{Acknowledgments}

This work was supported in part by grants from the National Institutes of Health (AI-10343 and HD-18661) and the March of Dimes Birth Defects Foundation. Stephanie Tzall is a Fellow of the Arthritis Foundation.

\section{References}

1. Hirschhorn, R. 1986. Inherited enzyme deficiencies and immunodeficiency: adenosine deaminase (ADA) and purine nucleoside phosphorylase (PNP) deficiencies. Clin. Immunol. and Immunopathol. 40:157-165.

2. Hirschhorn, R., and A. Ellenbogen. 1986. Genetic heterogeneity in partial ADA deficiency. II. Identification of at least three additional variants in five new patients. Am. J. Hum. Genet. 38:13-25.

3. Maniatis, T., E. F. Fritsch, and J. Sambrook. 1982. Molecular Cloning: A Laboratory Manual. Cold Spring Harbor Laboratory, Cold Spring Harbor, NY. $521 \mathrm{pp}$.

4. Martiniuk, F., M. Mehler, A. Pellicer, S. Tzall, G. LaBadie, C. Hobart, A. Ellenbogen, and R. Hirschhorn. 1986. Isolation of a cDNA for human acid alpha glucosidase and detection of genetic heterogeneity for mRNA in three deficient patients. Proc. Natl. Acad. Sci. USA. 83:9641-9644.

5. Orkin, S. H., S. C. Goff, W. N. Kelley, and P. E. Daddona. 1985. Transient expression of human adenosine deaminase cDNAs: identification of a nonfunctional clone resulting from a single amino acid substitution. Mol. Cell. Biol. 5:762-767.

6. Daddona, P. E., D. S. Shewach, W. N. Kelley, P. Argos, A. F. Markham, and S. H. Orkin. 1984. Human adenosine deaminase cDNA and complete primary amino acid sequence. J. Biol. Chem. 259:12101-12106.

7. Chirgwin, J. M., A. E. Pryzbyla, R. J. MacDonald, and W. J. Rutter. 1979. Isolation of biologically active ribonucleic acid from sources enriched in ribonuclease. Biochemistry. 18:5294-5299.

8. Adrian, G. S., D. A. Wiginton, and J. J. Hutton. 1984. Structure of adenosine deaminase mRNAs from normal and adenosine deaminase-deficient human cell lines. Mol. Cell. Biol. 4:1712-1717.

9. Favaloro, J., R. Treisman, and R. Komen. 1980. Transcription maps of polyoma virus-specific RNA: analysis by two-dimensional muclease S1 gel mapping. Methods Enzymol. 65:718-749.

10. Young, R. A., and R. W. Davis. 1983. Efficient isolation of genes by using antibody probes. Proc. Natl. Acad. Sci. USA. 80:11941198.

11. Gubler, U., and B. J. Hoffman. 1983. A simple and very effcient method for generating cDNA libraries. Gene (Amst.). 25:263269.

12. Feinberg, A. P., and B. Vogelstein. 1984. Addendum. a technique for radiolabelling DNA restriction enzyme fragments to high specific activity. Anal. Biochem. 137:266-267.

13. Bonthron, D. T., A. F. Markham, D. Ginsburg, and S. H. Orkin. 1985. Identification of a point mutation in the adenosine deaminase gene responsible for immunodeficiency. J. Clin. Invest. 76:894897.

14. Sanger, F., S. Nicklen, and A. R. Coulson. 1977. DNA sequencing with chain-terminating inhibitors. Proc. Natl. Acad. Sci. USA. 74:5463-5467.

15. Mierendorf, R. C., and D. Pfeffer. 1987. Direct sequencing of denatured plasmid DNA. Methods Enzymol. 152:556-563.

16. Martiniuk, F., A. Pellicer, M. Mehler, and R. Hirschhorn. 1985. Detection, frequency and stability of cotransformants expressing non-selectable human enzymes. Somatic Cell Mol. Genet. 12:1-12.

17. Spencer, N., D. A. Hopkinson, and H. Harris. 1968. Adenosine deaminase polymorphism in man. Ann. Hum. Genet. 32:9-14.

18. Tzall, S., A. Ellenbogen, F. Martiniuk, and R. Hirschhorn. 1987. Restriction fragment length polymorphisms (RFLPs) at the adenosine deaminase (ADA) locus and unusual restriction fragment 
patterns associated with partial deficiency of ADA. Am. J. Hum. Genet. 41:A243. (Abstr.)

19. Orkin, S. H., P. E. Daddona, D. S. Shewach, A. F. Markham, G. A. Bruns, S. C. Goff, and W. N. Kelley. 1983. Molecular cloning of human adenosine deaminase gene sequences. J. Biol. Chem. 258:12753-12756.

20. Valerio, D., M. G. C. Duyvesteyn, B. M. M. Dekker, G. Weeda, T. M. Berkvens, L. van der Voorn, H. van Ormondt, and A. J. van der Eb. 1985. Adenosine deaminase: characterization and expression of a gene with a remarkable promotor. EMBO (Eur. Mol. Biol. Organ.) J. 4:437-443.

21. Ingolia, D. E., M. R. Al-Ubaidi, C.-Y. Yeung, H. A. Bigo, D. A. Wright, and R. E. Kellems. 1986. Molecular cloning of the murine adenosine deaminase gene from genetically enriched source: identifcation and characterization of the promoter region. Mol. Cell. Biol. 6:4458-4466.

22. Wiginton, D. A., D. J. Kaplan, J. C. States, A. L. Akeson, C. M. Perme, J. BilykI, A. J. Vaughn, D. L. Lattier, and J. J. Hutton. 1986. Complete sequence and structure of the gene for human adenosine deaminase. Biochemistry. 25:8234-8244.

23. Youssoufian, H., H. H. Kazazian, Jr., D. G. Phillips, S. Aronis, G. Tsiftis, V. A. Brown, and S. E. Antonarakis. 1986. Recurrent mutations in haemophilia A give evidence for $\mathrm{CpG}$ mutation hotspots. Nature (Lond.). 324:380-382.

24. Akeson, A. L., D. A. Wiginton, J. C. States, C. M. Perme, M. R. Dusing, and J. J. Hutton. 1987. Mutations in the human adenosine deaminase gene that affect protein structure and RNA splicing. Proc. Natl. Acad. Sci. USA. 84:5947-5951.

25. Valerio, D., B. M. M. Dekker, M. G. C. Duyvesteyn, L. van der Voorn, T. M. Berkvens, H. van Ormondt, and A. J. van der Eb. 1986.
One adenosine deaminase allele in a patient with severe combined immunodeficiency contains a point mutation abolishing enzyme activity. EMBO (Eur. Mol. Biol. Organ.) J. 5:113-119.

26. Markert, M. L., M. S. Hershfield, D. A. Wiginton, J. C. States, F. E. Ward, S. H. Bigner, R. H. Buckley, R. E. Kaufman, and J. J. Hutton. 1987. Identification of a deletion in the adenosine deaminase gene in a child with severe combined immunodeficiency. J. Immunol. 138:3203-3206.

27. Berkvens, T. M., E. J. Gerritsen, M. Oldenburg, C. Breukel, J. T. Wijnen, H. van Ormondt, J. M. Vossen, A. J. van der Eb, and P. Meera-Khan. 1987. Severe combined immune deficiency due to a homozygous 3.2-kb deletion spanning the promoter and first exon of the adenosine deaminase gene. Nucleic Acids Res. 15:9365-9378.

28. Kyte, J., and R. H. Doolittle. 1982. A simple method for displaying the hydropathic character of a protein. J. Mol. Biol. 157:105132.

29. Garnier, J., D. J. Osguthorpe, and B. Robson. 1978. Analysis of the accuracy and implications of simple methods for predicting the secondary structure of globular proteins. J. Mol. Biol. 120:97-120.

30. Computer program supplied by Genetics Computer Group (GCG) University of Wisconsin, Madison, Wisconsin.

31. Hirschhorn, R., V. Roegner, T. Jenkins, C. Seaman, S. Piomelli, and W. Borkowsky. 1980. Erythrocyte adenosine deaminase deficiency without immunodeficiency. Evidence for an unstable mutant enzyme. J. Clin. Invest. 49:203-214.

32. Hirschhorn, R., F. Martiniuk, V. Roegner-Maniscalco, A. Ellenbogen, J.-L. Perignon, and T. Jenkins. 1983. Genetic heterogeneity in partial adenosine deaminase deficiency. J. Clin. Invest. 71:18871892. 